\title{
THE STUDENTS IN THE SYSTEM OF TERTIARY EDUCATION AS A MAIN FOCTOR FOR HR SUSTAINABLE CAPACITY EVALUATION - NATIONAL AND REGIONAL PERSPECTIVES
}

\author{
R. Radev* \\ University of National and World Economy, Sofia, Bulgaria
}

\begin{abstract}
The main goal of the current publication is to presents the specific result from the analysis of the most important PESTEL factors, identified as crucial for the HR Sustainable Capacity evaluation. It examines the students enrolled in higher education. The methodological framework, through which the goal is achieved, consists of four steps: first - the number and the types of higher educational institutions accredited in Bulgaria is identified (there are four types of 54 institutions); second - the gender structure of the students is analyzed, which testifies to the fact that there is domination of the female part of them (the number of the women amounts to 130 ' 803 , which is $54.0 \%$ of the total of students, the male students amounting to $112^{\prime} 396$ or $46 \%$.); third - the number and structure of the students from different degrees is presented, as well as their geographical distribution of the higher degree students - there are four main cities with more than 10' 000 bachelor students (Sofia, Plovdiv, Varna, Veliko Tarnovo), where $2 / 3$ of all bachelor and master degree students are educated. The conclusion is that the number of students (including graduating ones) studying at the different universities in Bulgaria are a very important part of the HR sustainable capacity evaluation on national and regional level.
\end{abstract}

Key words: Human resources, sustainable capacity, tertiary (higher) education, PESTEL analysis

\section{INTRODUCTION}

This paper represents part of the results from the study for defining Human resource capacity of Bulgaria and its main regions and cities. The main goal of this study is to identify the opportunities for business growth of the outsourcing companies in Bulgaria. There are three main groups of people, which are taken into account as main factors of human resources sustainability. The first group consists of people employed in outsourcing companies in Bulgaria and the companies from IT sector. The second group includes young work force of the age between 15-39 years. The third group includes two subgroups students graduating from their high schools (basic and vocational) and students enrolled in the system of tertiary education. The subject of interest in this paper is the HR capacity sustainability formed by the second subgroup,

\footnotetext{
*Correspondence to: Assoc. prof. Dr. Radko

Radev, University of National and World Economy, Sofia,Bulgaria,radko_radev@unwe.eu, 0894780098
}

which consists of above 240 thousands students enrolled in different degrees of higher education in Bulgaria. They represent approximately $15 \%$ of the young work force (15-39 years old). The conducted analysis shows that students studying their higher degrees of education are not evenly distributed among different regions and cities. The main goal of the paper is to identify the potential of the higher-degree-students as a main factor of the HR capacity sustainable of the country and its main cities and regions. In order to achieve this goal, the following main objectives were completed: 1) The methodological framework is presented; 2) The number and structure of universities according to their type and their geographical distribution are identified; 3 ) The number of students enrolled in the different degrees of their higher education; 4) their geographical distribution is identified. In conclusion, the main cities from the point of view of their HR capacity sustainability are presented. The results from the survey through which the detail profiling of students according to their qualitative characteristics (language 
and technical skills) are not presented in the current publication.

\section{METHODOLOGY}

The methodological framework through which the goal is achieved is based on the deductive approach and consists of four main steps. Through the first step the number and the types of higher educational institutions accredited in Bulgaria is identified. The second one clarifies the gender structure of the students. The third step helps to define the number and structure of the students from different degrees of the tertiary education and their geographical distribution. The current methodological framework is part of the more complex methodology by which the complex assessment of the HR capacity sustainability is made. This complex consists of four main steps.

- First - The position of the country according to Global Competitive Index and most problematic factors for doing business in Bulgaria are presented. This analysis helps understanding the attractiveness of Bulgaria as a country for doing business.

- Second - The results from analysis of the economic factor include: GDP, GDP per capita, unemployment rate, exchange rate in BGN vs. USD. This part of the report presents the macroeconomic environment in Bulgaria. It can be defined as an attractive one.

- Third - The main characteristics of the socio-demographic factors are identified as follows: population, natural growth, net migration, population density, and age structure. The most important

- Fourth - The results of analysis of Bulgarian education system include: secondary education - number and structure of secondary schools according to their type and number of students and graduating ones; higher education - number and structure of universities according to their type, location, and number of students studying. Through this analysis, the following two target groups are identified, namely: graduating students from secondary schools (high degree of education) and those ones studying at their bachelor and master's degrees programs. The numbers of these two groups are defined for the country as a whole, as well as for each specific territory (region, district and city) of interest.

\section{LITERATURE REVIEW}

Human resource management is philosophy. Among business organizations, there is a core understanding that Human Resource
Management takes the main role in their success. (1) There are two business models that are considered to seriously influence the modern human resource management - the academic circles of the US higher educational institutions and the Japanese School of Management. (2)

There is a well-founded belief that human resources management systems should be managed in accordance with the organization's strategy. (3) Moreover, to support this belief, you have to think about human resource management as a long term strategy. $(4,5)$ Considering to adopt Human resources this way, you will find out that they have an important role in the short term and long term business development. This understanding also is the heart of the concept once called "personnel", but today well known as "human resources" and "human capital". (6) According to modern management perspectives, human resource management must be accepted as an integral part of every manager's work. It means that it is part of the management functions. (7) Shortly the human resource management, and its functions are within the boundaries of every business organization. (8) Broadly, the human resource management concept is beyond the boundaries of business organizations. (9) In this case, its target is the growing and economically active, working population of the country. Including topics and questions like employment, unemployment, education, qualifications, health care, etc. The perception of human resources as management function contributes to identifying the HR Capacity and sustainability of a particular country as well as its regions, areas, and cities. Human resource management helps to assess the availability of human resources in these areas and its qualitative characteristics. The assessment of HR capacity sustainability is a key component in decision-making for business growth. (10, 11)

\section{RESULTS}

The result from the survey allows to identify the cities with biggest HR capacity sustainability according to the number of students enrolled in their master and bachelor degrees of education.

1) Types of Higher Education Institutions

There are 54 higher educational institutions accredited in Bulgaria, offering degrees at undergraduate and graduate levels. There are four types of higher education institutions: 1) Higher Education College (non-university 
higher education institution); 2) University; 3) Specialized Higher Education Institution Equivalent to Universities /Technical University and 4) Academy.

The academic year for most Bulgarian universities begins around October 1 and consists of fall and spring semesters. The academic year covers up to 30 weeks. Classes usually meet once a week for 75 minutes or for

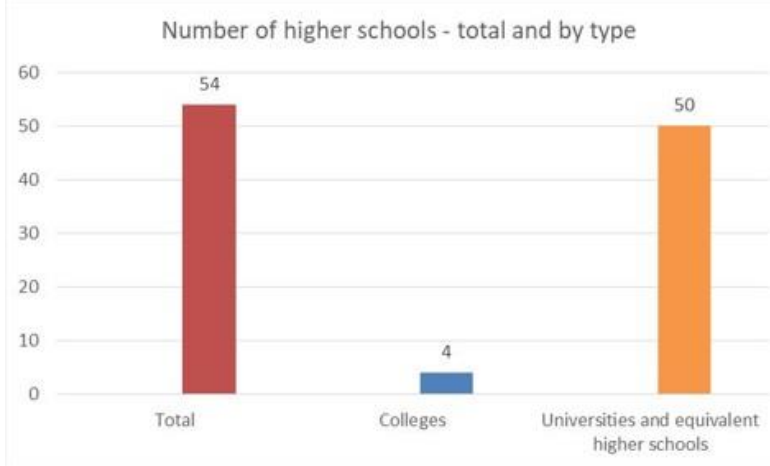

two 45-minute periods with a 15 -minute break in between.

The total number of higher schools is 54 from which 4 colleges and 50 universities and their equivalent. (Figure 1) Most of the higher schools are located in Sofia (21), followed by Plovdiv with 9, Varna with 6, Veliko Tarnovo -3 and Burgas and Blagoevgrad with 2. There are seven cities with one higher school.

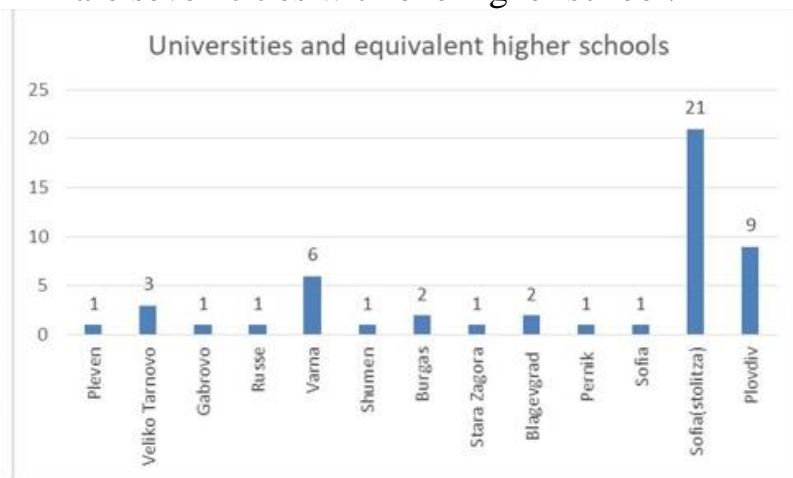

Figure 1. Number of higher schools by their type

2) Students enrolled in the four educational-qualification degrees

The total number of the students in Bulgaria enrolled in the four educational-qualification degrees ('Professional bachelor', 'Bachelor', 'Master' and 'Doctor') in the academic year 2016/2017 was 243.2 thousand, which is 16.8 thousand, or $6.4 \%$ less compared to the previous academic year.
The major part of the students from higher degrees of the educational system in Bulgaria are enrolled in the different bachelor programs. They represent $64 \%$ of all students or 155 , 237. The graduate students enrolled in master degree amounts to $77^{\prime} 627$ or $32 \%$. The remaining part of the students $(4 \%$, or 10 '335) are enrolled in professional bachelor degree (Figure 2).

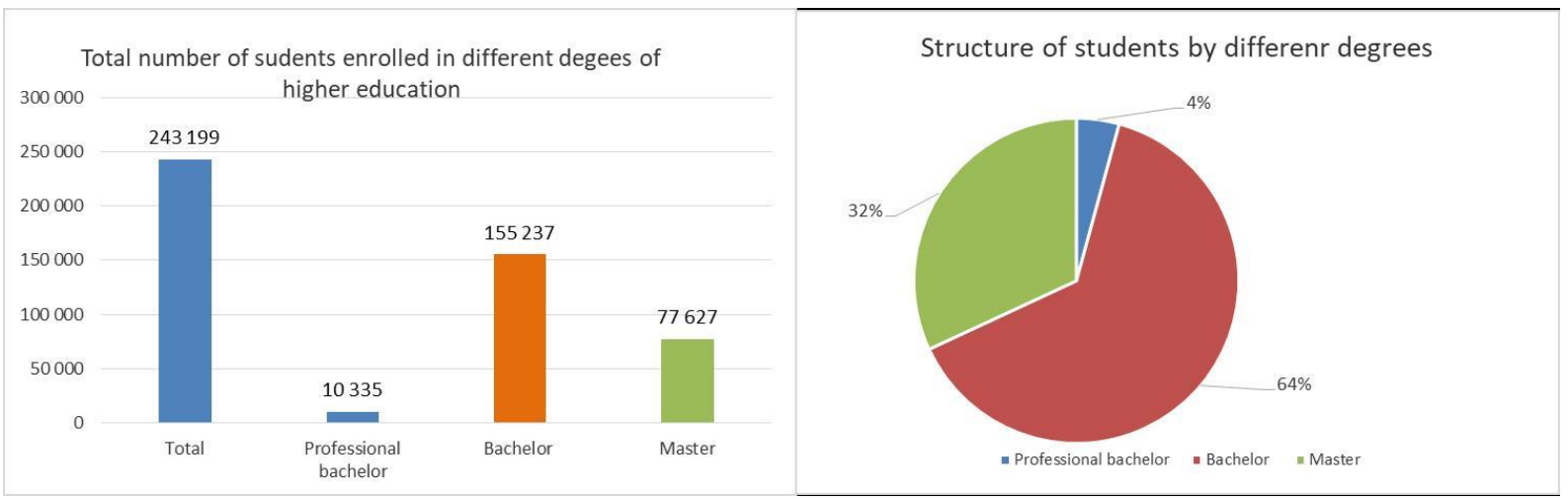

Figure 2. Number and structure of students enrolled in different degree of education

3) Students by gender and nationality (Bulgarian and foreigners)

In 2016/2017, students - Bulgarian citizens in universities and specialized higher schools were 243'199 or 95\%. Their number had decreased by 17'000 in comparison with the previous academic year or by $7.4 \%$. (Figure 3) The number of the foreign graduate students from all grade in the country was 13'170 persons, which is $13.5 \%$ more in comparison with 2015/2016 academic year. The largest share of foreign students came from Greece $26.9 \%$, followed by Turkey - $14.3 \%$, United Kingdom $-11.9 \%$ and Germany $-8.1 \%$ of the total number of foreign students.

The number of mobile students 5 enrolled in universities and specialized higher schools had increased from 11'147 persons in 2012/2013 to $13^{\prime} 042$ persons in the current $2016 / 2017$, or by $17.0 \%$. 


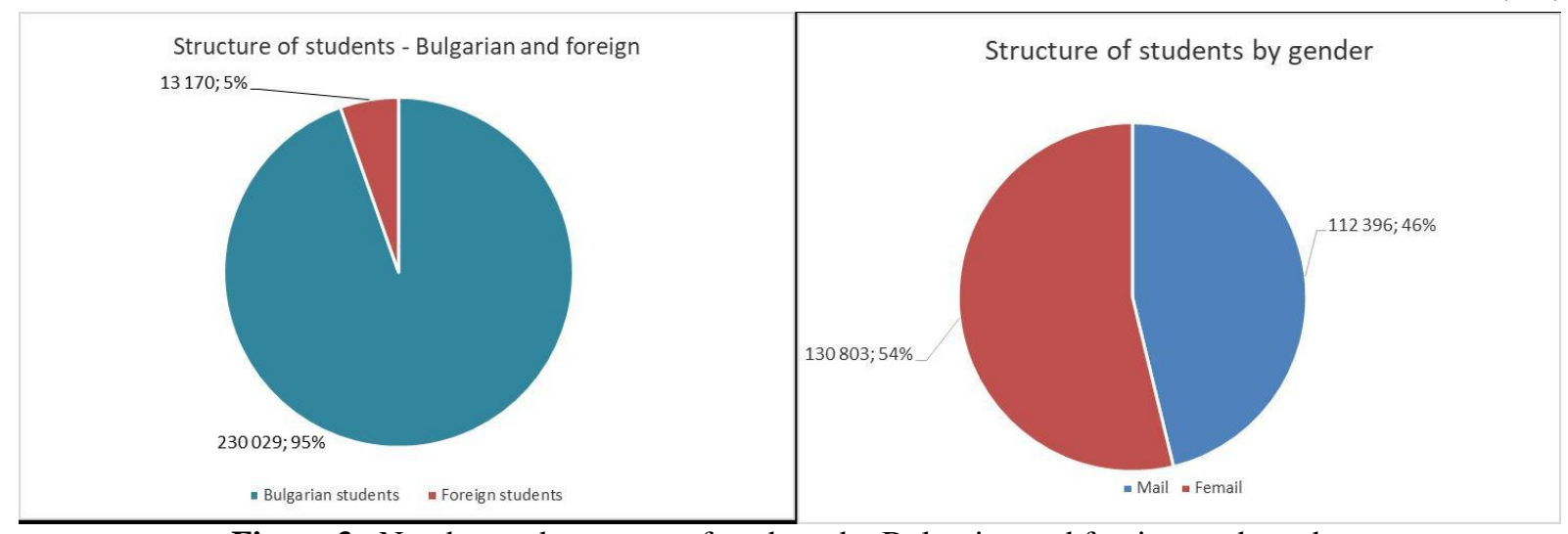

Figure 3. Number and structure of students by Bulgarian and foreign, and gender

Analyzing the gender structure of the students testifies to the fact that there is domination of the female part of them. The number of the women amounts to $130^{\prime} 803$, which is $54.0 \%$ of the total of students. On the other hand, the male students are 112'396, or 46\%. (Figure 3)

4) 'Professional bachelor' educational qualification degree

During the 2016/2017 academic year, for acquiring of the degree 'Professional bachelor', a total of 10'335 students were enrolled in colleges. In comparison with the previous year their number decreased with 1 284 , or with $11.1 \%$. From the total number of the students in colleges, 2 ' 375 , or $23.0 \%$ were enrolled in private colleges. In the structure of the students by fields of education, the highest relative share was found in the field of Health $26.3 \%$, followed by Personal services $-21.1 \%$, Engineering and Engineering Trades - 20.3\% and Business and Administration - $18.6 \%$. (Figure 4)

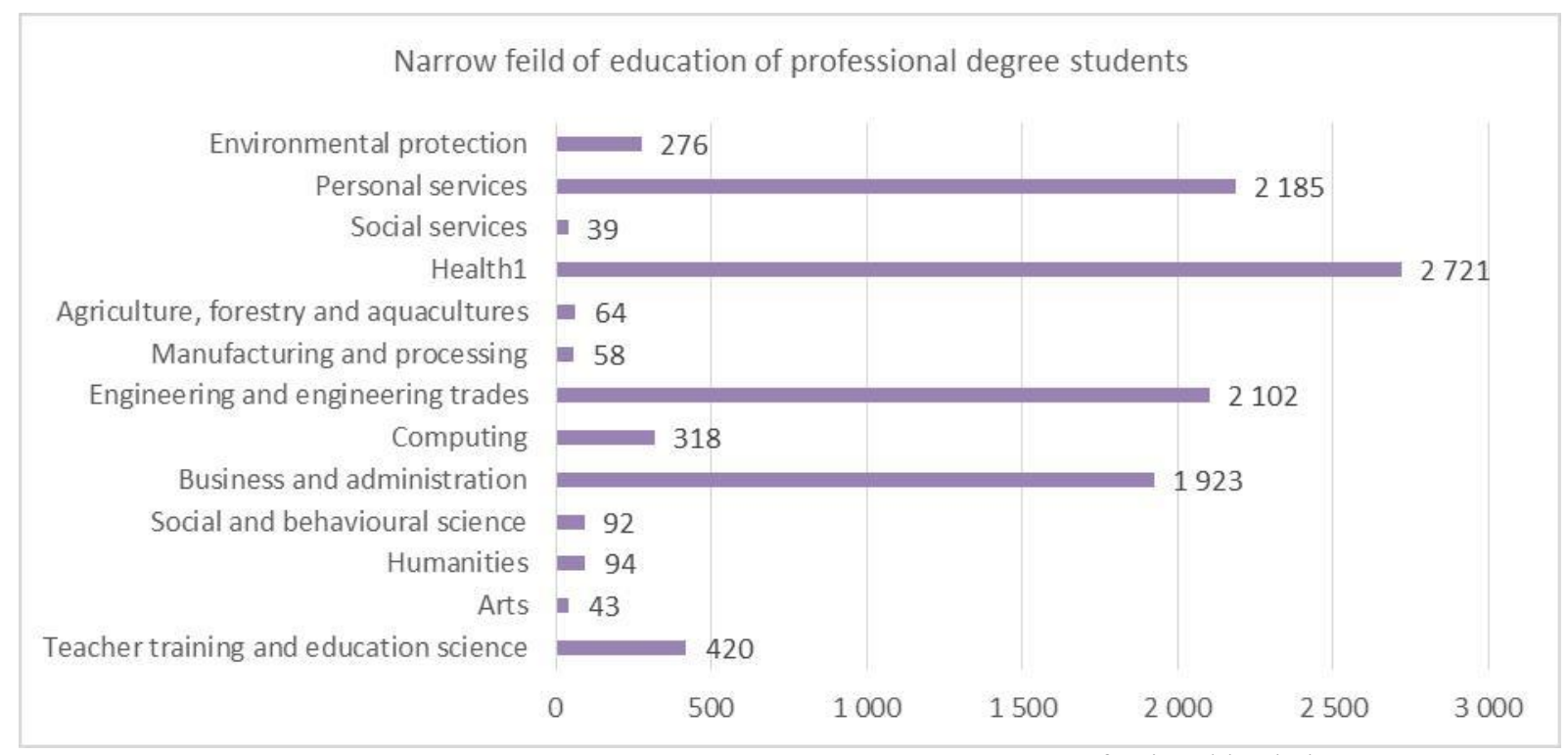

Figure 4. Narrow field of educational qualification degree "Professional bachelor"

- Regional distribution testifies that Sofia with its 3'232 students is the main center of the students from professional bachelor degree.

- Next city, with approximately 1'500 fewer students (or 1'780), is Plovdiv, followed by Varna, Burgas etc.

- It has to be noted that 1'404 students from the level of education, considered in the current paragraph, are enrolled in affiliates placed in four cities, which ate not involved in figure 30 .
- These cities, ranked in descending order according to the students who study there, are Dobrich with 757 students, Sliven - 231, Smolyan - 215 and Lovech-204.

5) Universities and equivalent higher schools ('Bachelor' and 'Master' educationalqualification degrees)

During the 2016/2017 academic year, the number of students, in the two educationalqualification degrees 'Bachelor' and 'Master', 
in universities and specialized higher schools was 232'864. Of them, 31'300 students or $13.5 \%$ of the total number were enrolled in private higher schools. The number of enrolled students in private higher schools declined with 31 ' 300 or $9.5 \%$ in comparison with the previous academic year. (Figure 5)
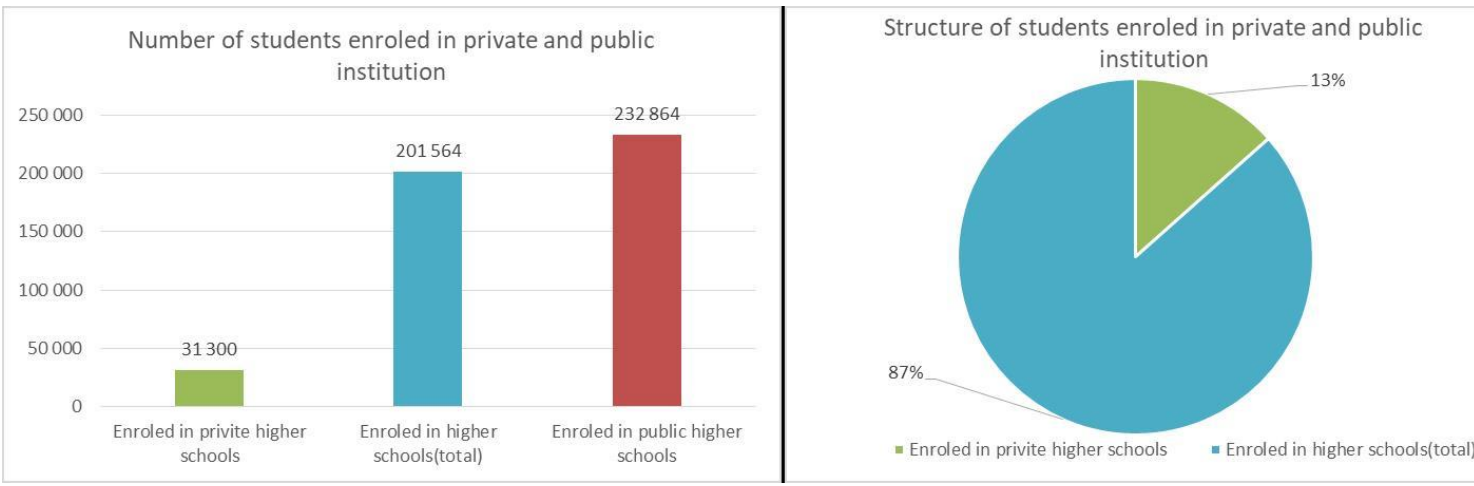

Figure 5. Higher degree Students enrolled in private and public institutions

6) Students in bachelor degree

Bachelor degree students by narrow field of education, new enrolled and graduated

The relative shares of students who have graduated were highest in the following fields: Business and Administration (29.9\%), Social and Behavioural Sciences (15.7\%) and Engineering and Engineering Trades (11.6\%). $18.0 \%$ of all graduates in the degree 'Bachelor' had graduated in private universities. (Figure 6)
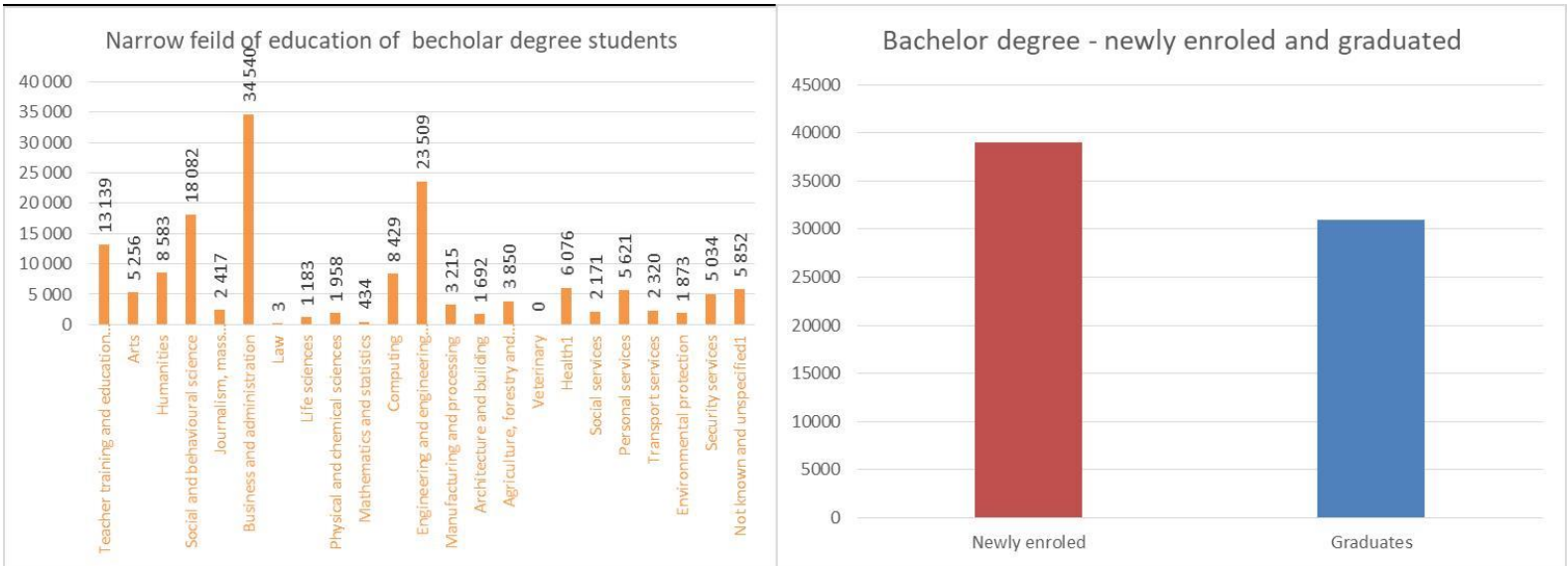

Figure 6. Bachelor degree students by narrow field, newly enrolled and students who have graduated

In the academic year 2016/2017, the number of newly enrolled students for acquiring the educational-qualification degree 'Bachelor' was $38^{\prime} 500$. Out of them $19^{\prime} 500$, or $50.5 \%$, were women. In the past 2016 , in the country 30 '900 students graduated with the degree 'Bachelor', of whom 18 ' 400 or $59.5 \%$ were women.

\section{Bachelor degree students by regions}

For the purpose of the current survey it is very important to find the information about geographical distribution of the higher degree students. There are four main cities with more than 10' 000 bachelor students (Sofia, Plovdiv, Varna, Veliko Tarnovo). They have educated more then $2 / 3$ of all bachelor degree students. The highest is the number of students who study in Sofia (Capital). There are 60'237 or approximately $40 \%$ of the total of bachelor degree students. (Figure 7)

The second place is taken by Plovdiv. It is proven to be the second most important academic center in Bulgaria and the leading one for the South part of the country. An evidence for this claim is the number of the bachelor students, which amounts to $222^{\prime} 455$ or $15 \%$ of the total. In other words, it means more than two times less than the number of students in Sofia and almost $50 \%$ more the next cities from this group - Varna and Veliko Tarnovo, where respectively $17^{\prime} 249$ and $15^{\prime} 784$ or $11 \%$ and $10 \%$ of the total study in bachelor degree programs there. 

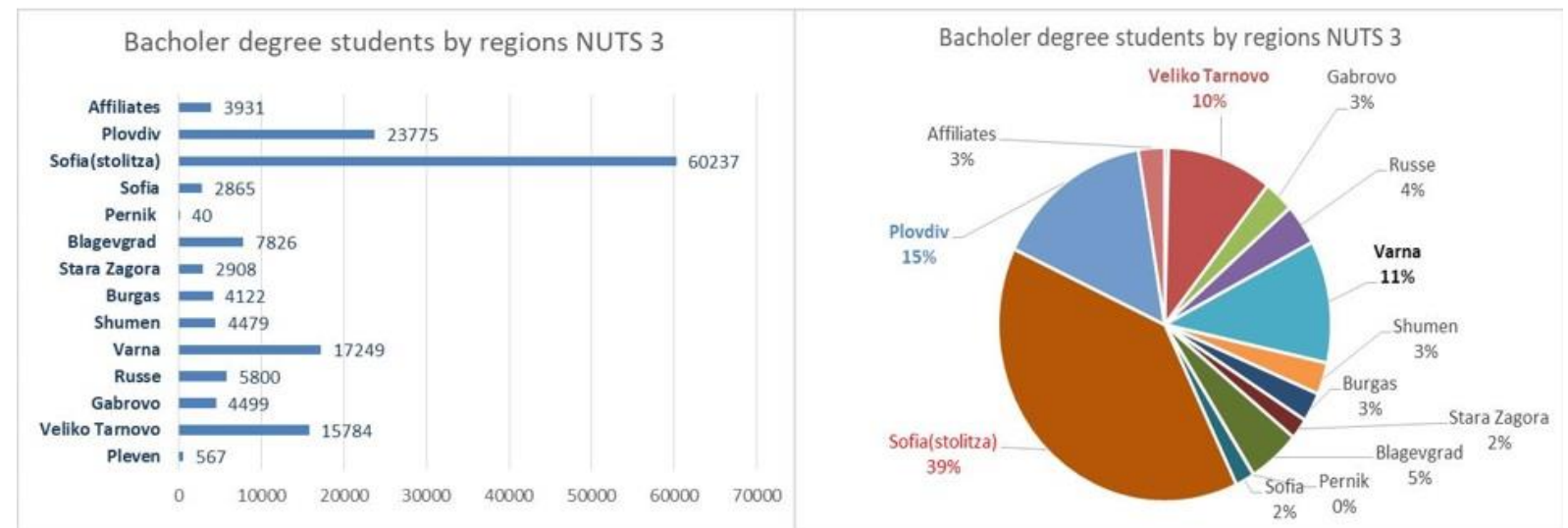

Figure 7. Number of geographical distribution of students from bachelor degree

The next group includes cities with between 4 and $10^{\prime} 000$ students. The first in this group and the forth in the country as a whole is Blagoevgrad with its almost 8'000 bachelor students (5\%), followed by Rousse (5'800 or $4 \%)$ and Gabrovo, Shumen, Burgas with more than 4 ' 000 or $3 \%$ each of them.

Students in master educational degree

Master degree students by narrow field of education, newly enrolled and students who have graduated
During the 2016/2017 academic year, the number of students in the educationalqualification degree 'Master' in universities and equivalent higher schools was 77'600 of whom $57.6 \%$ were women. Bulgarian citizens represented $88.6 \%$ of all enrolments and 9'000 or $11.6 \%$ of students enrolled in this educational-qualification degree were in private higher schools. (Figure 8)

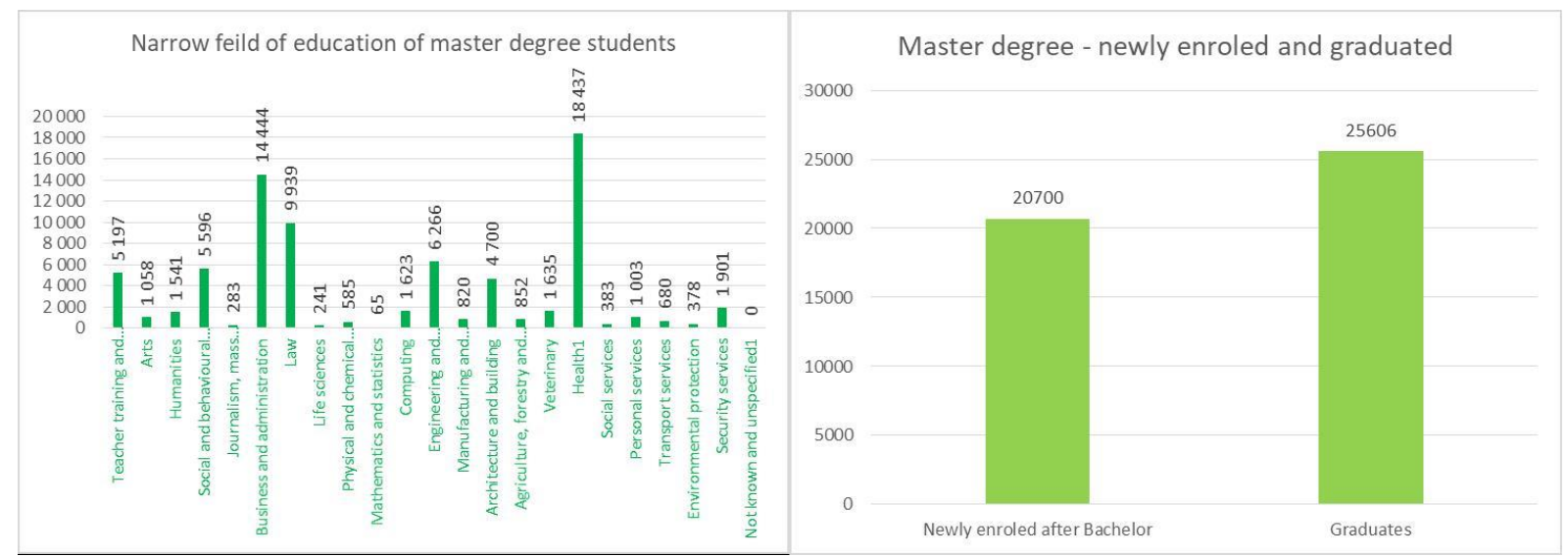

Figure 8. Master degree students by narrow field, new enrolled and graduated

The structure of students by narrow fields of education showed that the highest proportion of students were studying in the field of Health (23.8\%), followed by the field of Business and Administration (18.6\%) and Law (12.8\%). The lowest shares were registered in the fields of Journalism, mass communication and information $(0.4 \%)$, Life sciences $(0.3 \%)$ and Mathematics and Statistics $(0.1 \%)$.

New entrants in master programs after graduations of educational-qualification degree 'Bachelor' were 20 '700 of whom $4.0 \%$, were enrolled after graduation of level 'Professional Bachelor'.
In 2016, in the country 25, 606 students graduated with the degree 'Master', of whom almost two-thirds $(64.2 \%)$ were women. The relative shares of graduated students were highest in the fields: Business and Administration (32.1\%), Social and Behavioural Sciences (11.0\%) and Teacher training and education science $(10.2 \%)$. The lowest relative shares were found in the fields: Environmental protection (0.7\%), Journalism, mass communication and information $(0.6 \%)$, Veterinary $(0.3 \%)$ and Mathematics and statistics $(0.1 \%)$ of the total number of graduates in Master degree. $13.2 \%$ of all graduates in the degree 'Master' had graduated in private universities. 
Master degree students by regions

Geographical distribution is different to some extent from that which is observed for bachelor degree. Sofia is again with the highest importance with 38'035 master students enrolled, which represents $48 \%$ of the total. With three times less, second place is for Plovdiv, where students who are studying Master degree students by regions NUTS 3

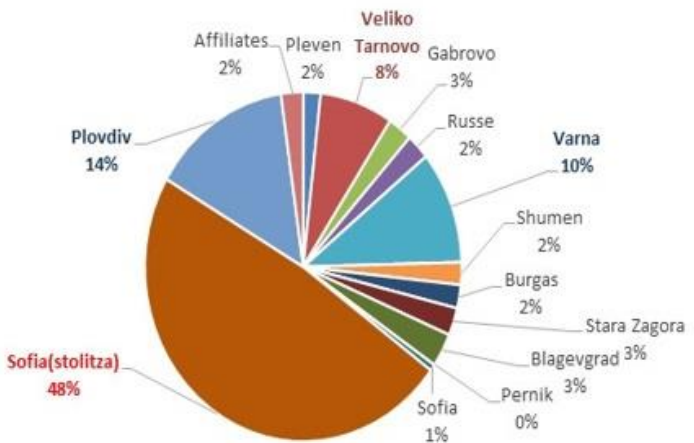

master degree amount 11 ' 313 or $14 \%$ of all the master students, followed by Varna - $10 \%$ (8'251 students) and Veliko Tarnovo - 8\% (5'899 students). These four cities concentrate $70 \%$ of the students from master degree in Bulgaria. In seven of the academic cities there are between 1'300 and 2'500 students educated in this degree. (Figure 9)

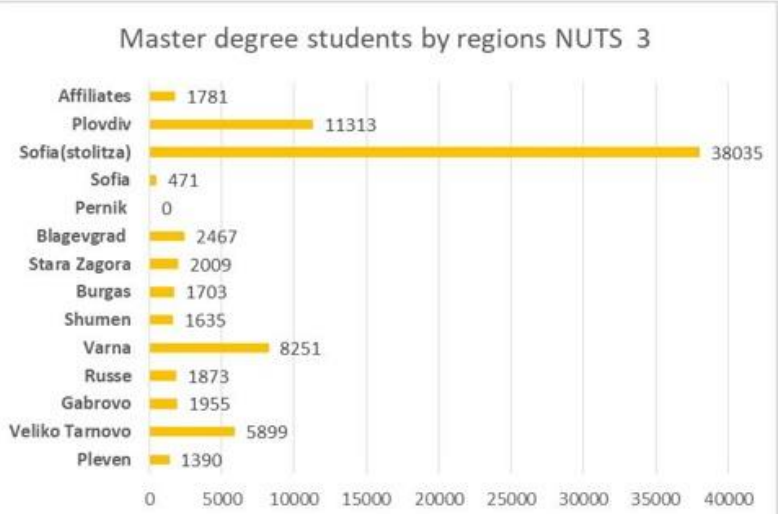

Figure 9. Number of geographical distribution of students from master degree

7) Graduating students from all degrees in higher education

There are 30' 895 students who graduate bachelor degree there annually, which is a little more than $50 \%$ of all graduating students in
Bulgaria. Master degree is graduated by $25^{\prime} 606$ or $43 \%$ of the total. The smallest is the number of these students who graduate their doctorate -1 '446 or $2 \%$ and professional bachelor -2 ' 418 or $4 \%$. (Figure 10)

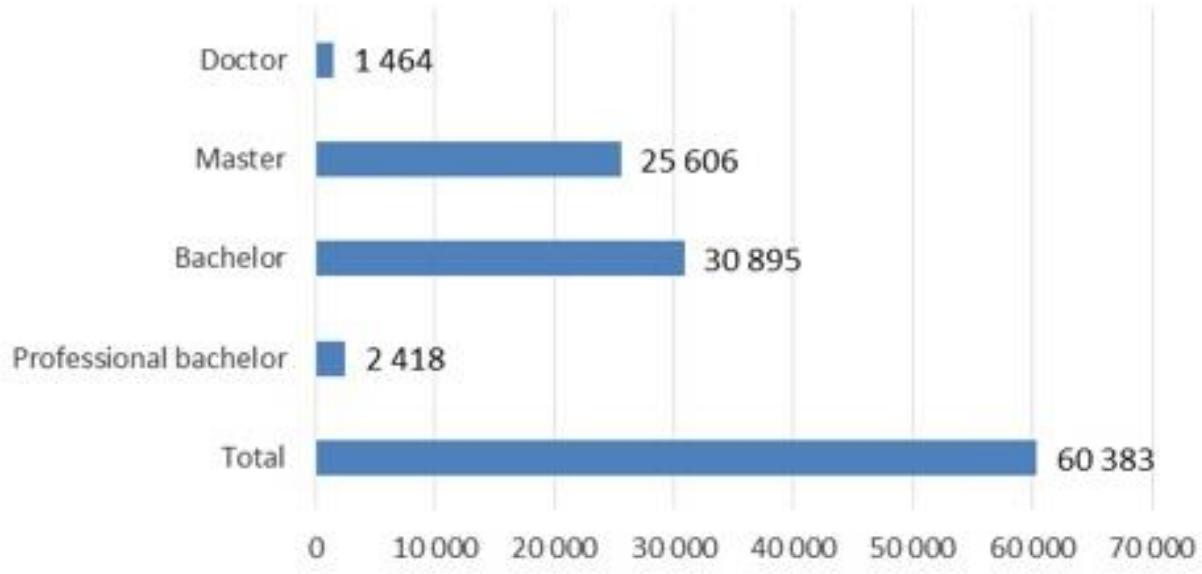

Figure 10. Graduating students from all degrees of higher education

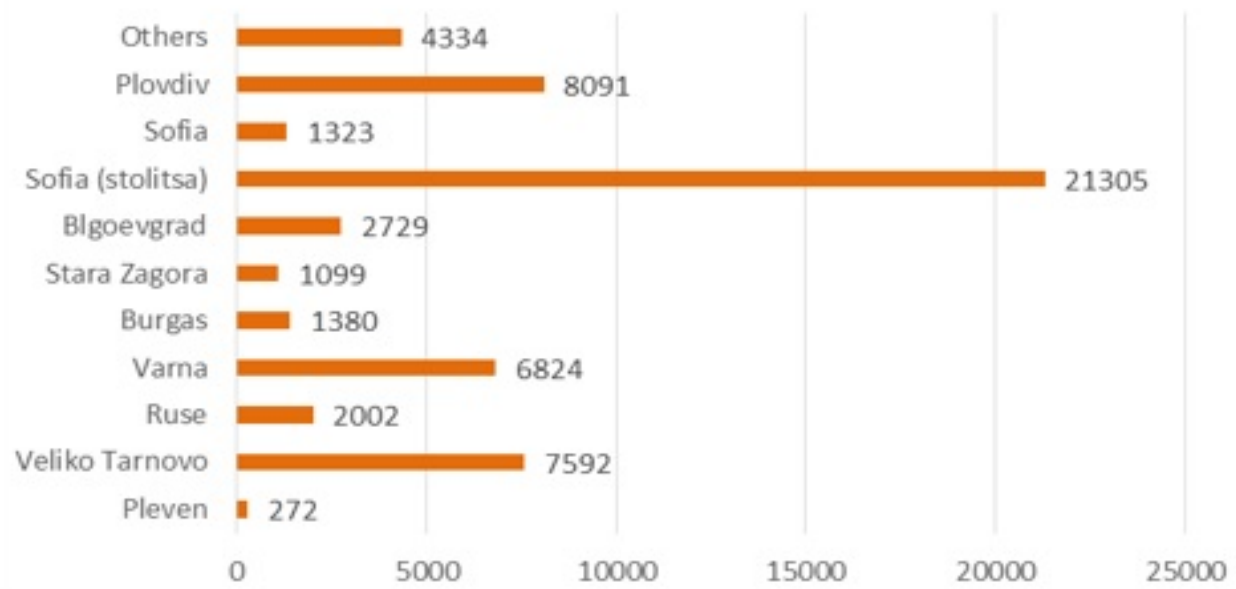

Figure 11. Graduating students from all degrees of higher education in the nine cities of interest 
The highest number of students graduating their higher degrees, as it can be expected, is registered in Sofia (21'305), followed by Plovdiv (8'091), Veliko Tarnovo (7'592) and Varna (6824). The next important group of cities from this point of view are Rousse (2’202), Burgas (1’380), Sofia region (1’323).

\section{(Figure 11)}

\section{CONCLUSIONS}

The conclusion is that the number of students (including graduating ones) studying at the different universities in Bulgaria are very important part of the HR sustainable capacity evaluation on national and regional level. The analysis is conducted for each one of the nine cities of interest and for the country as a whole. This helps outsourcing companies to define where (on which cities) to focus their further researches. Sofia is the city with the greatest potential (HR Capacity sustainability) the data shows that the potential of the students at universities - 101'505 (46\% of the total). Plovdiv is on the second place after Sofia in all three groups - the numbers of students at universities is $36^{\prime} 868$, which is 2.8 times below the number in Sofia. Third place is for Varna - there is a bigger difference between students enrolled at universities. The number of students in Varna (26'886) is 1.4 times less than in Plovdiv. Veliko Tarnovo takes fourth place in the group of students at universities there are $21^{\prime} 683$ enrolled students. This is 3 times more than the number of students in Burgas and 30\% less than those in Varna. Blagoevgrad takes fifth place in the group of students at universities with 10'861 students, which is 2 times less than Veliko Tornovo and $37 \%$ more than Rousse (7'673). Rousse takes sixth position in the group of graduating from high schools (after Stara Zagora) and fifth studying at university (after Blagoevgrad). Stara Zagora has the similar positions to Rousse. Burgas takes sixth place in the group of students at universities 7'142 (after Veliko
Tarnovo and Blagoevgrad). The number of students at universities in Burgas is 3.7 times less than in Varna and 2.7 times less than in Veliko Tarnovo.

\section{REFERENCES}

1. McGregor, D. (1985). The Human Side of Enterprise. (25thanniversary edition) New York: McGraw-Hill, pp. 33-48.

2. Witzel, M., A History of Management Thought, 2-d Edition.Routlege, London and New York, 2016.

3. Fombrun, C.J., Tichy, N.M. and Devanna, M.A., Strategic Human Resource Management. Wiley, New York, 1984.

4. Beer, M., Spector, B., Lawrence, P.R., Quinn Mills, D. and Walton, R.E., Human Resource Management. New York: Free Press, 1984.

5. Kearns, P., HR Strategy: Creating Business Strategy with Human Capital. Routledge, Second edition, ELSEVER, 2010.

6. Schermerhorn, J., R., Introduction to Management, John Wiley \& Sons, 2011.

7. Price, A., HumanResource Management in a Business Context, 2-th Ed. Thompson, 2004.

8. Armstrong,M, A Handbook of Human Resource Management Practice, 10-th edition. Kogan page, London, 2010.

9. Ulrich, D., Brockbank, W., Younger, J., Nyman, M., Allen, J., HR Transformation: Building Human Resources From the Outside In. McGraw Hill Professional, 2009.

10.Ehnert, I., Harry, W., Zink, K. J., Sustainability and Human Resource Management: Developing Sustainable Business Organizations. Springer Science \& Business Media, 2013.

11.Ehnert, I., Sustainable Human Resource Management: A conceptual and exploratory analysis from a paradox perspective, Springer Science \& Business Media, 2009. 